\title{
Operaciones encubiertas, su obscuridad legal: Figura vulnerante de las garantías de certeza y de seguridad jurídica
}

\section{Undercover operations, their legal obscurity: vulnerant figure of legal certainty and security guarantees}

\section{AUTOR: Lucía Almaraz Cázarez}

SUMARIO: I. Vigilancia encubierta. II. Las operaciones encubiertas, como técnica de investigación. III. El agente infiltrado o encubierto. IV. Principios de las operaciones encubiertas. V. Marco legal que sustenta la figura de las operaciones encubiertas. VI. Operaciones encubiertas en el periodo 2006 - 2012. VII. A manera de conclusión.

Resumen: La figura de la operación encubierta y con ello el agente infiltrado, se justifica bajo la necesidad de realizar investigaciones en organizaciones delictivas internacionales. Las preguntas que respondemos en el presente trabajo son: ¿Existen leyes que permiten su uso? ¿Qué requisitos previos deben satisfacerse para poder utilizarlas? ¿Quién autoriza su empleo? ¿Existen plazos dentro de los cuales pueden usarse? ¿Existe alguna supervisión o vigilancia independiente de estas técnicas? ¿Pueden usarse en juicio los resultados de estas técnicas? ¿Existen normas especiales de admisibilidad de la prueba?.

La inquietud de analizar las operaciones encubiertas es analizar si esta figura es vulnerante de los derechos humanos de las personas sujetas a esta técnica, y con ello verificar si contamos con un soporte jurídico amplio y transparente que proporcione a la ciudadanía la certidumbre de legalidad que requiere la implementación de este tipo de figuras legales.

Palabras clave: Agente encubierto, delincuencia organizada, operación encubierta, técnica de investigación.

Abstract: The figure of the covert operation and thus the undercover agent, is justified under the need for research in international criminal organizations. The questions to answer in this paper are: Are there laws that allow its use? What prerequisites must be satisfied to use them? Who authorizes their use? Are there deadlines within which can be used? Is there any independent oversight or monitoring of these techniques? Are the results of these techniques can be used in court? Are there special rules for admissibility of evidence? Concern analyzing covert operations is to analyze whether this figure is Vulnerant human rights of persons subject to this technique, and thus verify if we have a comprehensive and transparent legal support to citizens to provide the legal certainty required the implementation of such legal concepts. 


\section{Vigilancia encubierta}

La vigilancia encubierta es un método particularmente intrusivo de reunir información. El uso de medidas de vigilancia encubierta supone el logro de un delicado equilibrio entre el derecho a la privacidad del sospechoso y la necesidad de investigar los delitos graves. Las disposiciones relativas a la vigilancia encubierta deberían tener plenamente en cuenta los derechos del sospechoso. Existen diversas decisiones adoptadas por tribunales y órganos internacionales de derechos humanos sobre la permisibilidad de la vigilancia encubierta y los parámetros de estas medidas. Conviene consultar dichas decisiones. En el artículo 116 del Código Modelo de Procedimiento Penal (PROYECTO, 30 de mayo de 2006) se hace un extenso comentario sobre el tema. En las sociedades en que las autoridades ejercen un estricto control sobre la población, el uso de estas técnicas puede ser indiscriminado. En otros sistemas se exige la observancia de varias salvaguardias estrictas para prevenir los abusos, incluida la exigencia de que el delito sea grave, que el uso de la técnica sea vital para el caso y que pruebas esenciales no puedan obtenerse si no es por medios intrusivos. Es común que exista supervisión judicial $\mathrm{o}$ independiente, requisito que recogen las normas internacionales de derechos humanos.

Se utilizan las siguientes técnicas de vigilancia encubierta:

- Interceptación de telecomunicaciones.

- Interceptación de correo electrónico.

- Interceptación de correo.

- Uso de dispositivos de escucha.

- Uso de dispositivos de rastreo.

- Uso de equipos de vigilancia.

- Uso de vigilancia fotográfica.

- Uso de identidades falsas personales o de empresas.

- Inspección encubierta de cartas, paquetes, contenedores y encomiendas. 
- Compra simulada de un artículo.

- Simulación de comisión de un delito de corrupción.

- Vigilancia encubierta en tiempo real de transacciones financieras.

- Uso de dispositivos de rastreo y de determinación de la posición.

Nuestra situación actual, de crisis en el sistema de justicia penal y altos niveles de inseguridad, ha propiciado que junto con la asignación de mayores partidas presupuestales dedicadas al mantenimiento de la seguridad ciudadana y el frontal combate del crimen se aprueben mandatos penales o procesales más duros y represivos a fin de lograr reducir los niveles de impunidad y de seguridad pública. En este sentido, medios extraordinarios de investigación, como el agente provocador, operaciones encubiertas y entregas vigiladas encuentran un espacio propicio para introducirse al derecho positivo.

\section{Las operaciones encubiertas, como técnica de investigación}

El agente encubierto es un medio extraordinario de investigación en el que se apoyan cuerpos de policía -de diversos países- para conseguir mejores resultados en el combate contra la criminalidad. Con esta fórmula de investigación se permite la penetración o infiltración del Estado, por medio de un agente de policía, que oculta su verdadera identidad, a un grupo de delincuencia a fin de obtener información sobre sus miembros, estructura, modus operandi, campos de operación, así como para adquirir pruebas sobre la ejecución de hechos criminales, para que sus integrantes puedan ser sentenciados en una causa penal por los ilícitos que hubiesen cometido.

Una operación encubierta es aquella acción de investigación que ejecuta la autoridad con el propósito de hacer creer a los delincuentes que se está actuando a la par de ellos, es decir, que también los que actúan en la operación encubierta, que son los agentes de policía infiltrados, lo hacen ilícitamente, sin pensar los miembros de la organización delictiva, que es una farsa, un engaño, con el objeto de hacer creer que igual que ellos se está actuando impunemente.

Por otro lado, es necesario precisar que toda infiltración policial se desarrolla en dos etapas: 
1) Ubicación y toma de contacto del infiltrado con el medio delictuoso que se intenta indagar, momento en que las operaciones de éste se orientarán principalmente, por medio del engaño, en crear relaciones de confianza con los individuos, las cuales les permitirán el progreso de su averiguación criminal.

2) En la que el agente infiltrado podrá más oportunamente llevar a cabo las tareas de pesquisa de información e indicios de actividad ilícita que les han encomendado.

La infiltración policial, es una técnica prorrogable en el tiempo, pues la autorización de una identidad supuesta a un funcionario policial -es su condición de agente encubierto- puede ser por diferirse según las necesidades de la investigación. Durante todo este tiempo el agente encubierto estará legítimamente habilitado para ejecutar acciones en todo lo relacionado con la investigación concreta, así como a participar en el tráfico jurídico y social bajo su identificad supuesta.

En principio, las conductas ilícitas que en cumplimiento de su misión un funcionario policial que actúa como agente encubierto dentro de una organización con fines ilícitos podría interpretarse especialmente justificadas y, por tal motivo, exentas de responsabilidad criminal al obrar en el ejercicio legítimo de un oficio o encargo. Sin embargo, esta justificación opera sólo en aquellos comportamientos que se realicen en forma necesaria del desarrollo de la propia investigación criminal ${ }^{1}$.

\section{El agente infiltrado o encubierto}

La figura del agente encubierto es un medio extraordinario de investigación en el cual se apoyan Cuerpos de Policía de diversos países con el propósito de lograr mejores resultados en el combate contra la criminalidad organizada. La técnica de infiltración policial en el ámbito delictivo no es nueva. Ese procedimiento se ha venido utilizando por largo tiempo aunque no estuviera previsto en la legislación. Se trata de los llamados informantes. Esta actividad debe entenderse como la de infiltrados que sin conculcar legalidad alguna, se encamina al descubrimiento de delitos y la acumulación de pruebas, lo cual se

${ }^{1}$ Guillen López, Germán, La investigación criminal en el sistema penal acusatorio, disponible: http:// biblio.juridicas.unam.mx/libros/libro.htm?|=3454, verificada el 03 de diciembre de 2015. 
dificulta extraordinariamente en la criminalidad organizada, por lo cual se le considera como uno de los instrumentos de investigación penal clave en el combate de esta especie de delincuencia. Puede actuar con retribución de sus servicios por parte del Estado o por ánimo de colaborar con la justicia. Estos colaboradores no buscan la comisión de delitos sino conocer los medios, las formas o los canales por lo que ese tráfico ilícito se desenvuelve; es decir, se pretende la obtención de pruebas con relación a una actividad criminal que ya se está produciendo, pero de la que únicamente se abrigan sospechas.

El agente encubierto supone una evolución en la lucha contra la delincuencia organizada. Se caracteriza por su infiltración en dinámicas delictivas, y por el uso de una identidad supuesta, para la consecución de pruebas que inculpen a los sospechosos de actividades propias del crimen organizado; se integra en la estructura de una organización que tenga fines delictivos para, desde dentro de la misma, obtener pruebas suficientes que permitan la condena penal de sus integrantes y, como fin ultimo, la desarticulación de la organización criminal ${ }^{2}$.

\section{a) La figura del agente encubierto encuentra sus raíces en el sistema inquisitivo}

El agente encubierto supone la presencia continua del Estado en la esfera de intimidad de unas personas, al punto que puede saber mucho más de ellas que aquello estrictamente necesario para obtener una condena judicial.

El agente encubierto es un funcionario policial o un miembro de las fuerzas de seguridad que se infiltra en una organización criminal para obtener información de su estructura y funcionamiento. Para ello se vale de una identidad falsa y de una autorización judicial para cometer delitos y así poder ganarse la confianza de los miembros de la organización. El objetivo final es que a partir de los datos que el agente encubierto aporte a la investigación, sea posible reunir prueba a cargo contra los integrantes de la asociación criminal y así poder perseguirlos penalmente.

El agente encubierto obtiene información del propio investigado, sin que se reúnan los requisitos establecidos por la ley procesal en relación a la declaración del imputado. La regulación de forma

\footnotetext{
${ }^{2}$ Rivero Evia, Jorge, Los agentes clandestinos y el debido proceso, Revista del Instituto de la Judicatura Federal No. 28, disponible: http://www.ijf.cjf.gob.mx/publicaciones/revista/28/Los_agentes_ clandestinos.pdf, verificada el 06 de diciembre de 2015.
} 
establece que el acusado sólo puede ser interrogado por el juez, debe ser informado del derecho que le asiste de contar con un abogado defensor y de conferenciar con él antes de declarar. A su vez, se le debe indicar cuál es el hecho cuya comisión se le atribuye a cuáles son las pruebas en su contra.

El uso de agentes encubiertos abre las puertas a un Estado sin limitaciones ni sujeto a control alguno. Dejamos de ser protegidos por el Estado para transformarnos en sus victimas. La utilización de un método de investigación tan amplio y violatorio de derechos y garantías fundamentales nos conduce por un camino peligroso. Así, podría arribarse a una instancia en la que cualquiera de las personas que convive con nosotros podría ser un miembro de las fuerzas de seguridad que oculta su identidad con la finalidad de saber más de nuestras vidas.

El empleo de agentes encubiertos contraviene derechos constitucionales bajo el amparo de una pretendida finalidad de lograr una mayor seguridad. Se trata de utilizar el proceso penal con fines persecutorios y de vigilancia social. Consiste en negar derechos y garantías individuales en nombres de la "necesidad social" o la "emergencia" y el Estado se excluye a si mismo de todo control ${ }^{3}$.

\section{Principios de las operaciones encubiertas}

- Excepcionalidad: Esta técnica se aplica de manera excepcional en caso de ausencia o insuficiencia de medios de prueba.

- Jurisdiccional: Deben ser necesariamente autorizadas por autoridad jurisdiccional competente.

- Pertinencia: Para la ejecución de estas técnicas se tomará en cuenta la relación costo-beneficio y la complejidad de la investigación.

- Proporcionalidad: Se aplicará siempre y cuando el interés publico o general de la sociedad sea superior al interés privado.

\footnotetext{
${ }^{3}$ Lamarre, Flavia, Agentes encubiertos y criminalidad organizada: Derecho y Demagogia, Lecciones y Ensayos, nro. 88, 2010, disponible: http://www.derecho.uba.ar/publicaciones/lye/revistas/88/ lecciones-y-ensayos-88-paginas-175-195.pdf, verificada el 26 de noviembre de 2015.
} 
- Reserva: Las actuaciones del agente encubierto, se desarrollarán con la más estricta reserva y confidencialidad, velando por la seguridad, la vida e integridad física de quienes la ejecuten.

- Especialidad:Tanto el fiscal como los investigadores policiales, que realicen estas actividades, deberán ser idóneos y especializados en las técnicas de investigación.

- Legalidad: En la aplicación de esta técnica, debe respetarse la Constitución Política del Estado, las convenciones y tratados internacional vigentes, leyes y otras normas.

- Celeridad: En la tramitación procesal de estas técnicas deberá actuarse con prontitud y diligencia, por la finalidad de las mismas, bajo prevenciones de ley.

\section{a) Perfil del agente infiltrado}

1. Autonomía personal para la toma de decisiones adelantándose a las situaciones, incluida la habilidad para enfrentarse a problemas y resolverlos.

2. Eficiente, eficaz y competente.

3. Capacidad para adaptarse al medio; para mimetizarse con él.

4. Alta inteligencia, incluida la emocional.

5. Equilibrado, calmado, que guarde el control.

6. Capacidad de comunicación a todos los niveles; oral, gestual, lenguaje verbal y no verbal.

7. Perfil de vendedor

8. Empatía, es decir, tener la capacidad de ponerse en el lugar del otro e interpretar las situaciones desde su punto de vista.

9. Confianza en sí mismo con un alto grado de control interno.

10. Dureza como equivalente a poco sentimental; no tiene que ser necesariamente frío, pero si que no se deje llevar por sus sentimientos.

11. Flexibilidad, en el sentido de ser tolerante con los valores culturales y morales de otros.

12. Tolerancia a la critica y a la frustración; debe ser independiente, que no necesite la aprobación del medio. 
13. Confidencialidad y discreción.

14. Capaz de asumir riesgos sin llegar a ser temerario.

15. Preferentemente soltero y sin hijos.

16. Resistente al dolor y con aguante físico considerable

17. Debe ser una persona vulgar y corriente. Sin manías.

18. Edad: el rango ideal es entre 25-45 años, puesto que si es demasiado joven se corre el riesgo de que cometa errores por la necesidad de reafirmarse y demostrar su valía; por el contrario, si es demasiado mayor se temen en exceso las pérdidas y el cambio es mucho más difícil de asumir, así como el adaptarte a él.

19. Aspecto físico corriente.

20. Culto. Se necesita un nivel cultural medio-alto. ${ }^{4}$

\section{b) Características de la operación encubierta}

- Autorizada por el juez de control.

- Que existan indicios suficientes.

- Idoneidad de la medida.

- Necesidad de la medida

- Gravedad de la conducta investigada.

- Motivación.

\section{c) Actividades que pueden llevar a cabo el agente encubierto}

- Adquirir objetos, efectos o instrumentos del delito.

- Demorar o diferir la incautación de dichos objetos hasta el momento en que la evolución de la investigación lo aconseje.

- Transportar esos objetos, efectos o instrumentos.

\footnotetext{
${ }^{4}$ Del Pozo Pérez, Marta, El agente encubierto como medio de investigación de la delincuencia organizada en la ley de enjuiciamiento criminal española, disponible: http://revistas.javerianacali.edu. co/index.php/criteriojuridico/article/viewFile/260/1023, verificada el 03 de octubre de 2015.
} 
- Participar en el tráfico jurídico y social bajo identidad supuesta.

\section{d) Funciones del agente encubierto}

- Infiltrarse y/o penetrar en la actividad criminal sujeta de investigación.

- Obtener información y/o elementos de convicción para el caso.

- Identificación e individualización de personas, cosas, bienes y lugares.

- Informar al fiscal periódica y oportunamente sobre hechos y actuaciones sin perjuicio de hacerlo mediante el asignado al caso.

- Realizar otras labores que sean necesarias para el cumplimiento efectivo de la misión.

\section{e) Medidas de protección}

- Las medidas adecuadas para el ejercicio y seguridad del agente encubierto son:

- Grupo de apoyo permanente encargado de su seguridad física.

- Apoyo psicológico durante y después de la misión de manera periódica de acuerdo a la pertinencia y las posibilidades de cada institución.

- Prioridad de la inclusión en el programa de protección a testigos, si fuera necesario.

- Protección permanente a su familia.

- La identidad del agente encubierto, se conservará en estricta confidencia y por el tiempo que sea necesario.

- En caso necesario y cuando sea imprescindible para resguardar la integridad del agente encubierto, podrá cambiar su identidad.

\section{f) Formas de conclusión de la misión}

- Por solicitud del agente infiltrado. 
- Por decisión del fiscal en coordinación con el asignado al caso a los jefes policiales.

- Por incumplimiento de la misión

- Por incapacidad sobreviniente.

- Por muerte del agente encubierto ${ }^{5}$.

\section{Marco legal que sustenta la figura de las operaciones encubiertas}

\section{a) Marco internacional.}

La Convención de las Naciones Unidas contra la Delincuencia Organizada Transnacional de diciembre de 2000, identificó a estos procedimientos como técnicas especiales de investigación en el apartado primero del artículo 20. En dicho artículo la Convención de Palermo, como también se le conoce a este instrumento internacional, precisabala necesidad de que los estados adopten tales procedimientos para combatir el crimen organizado.

\section{Artículo 0..}

Técnicas especiales de investigación.

1. Siempre que lo permitan los principios fundamentales de su ordenamiento jurídico interno, cada Estado Parte adoptará, dentro de sus posibilidades y en las condiciones prescritas por su derecho interno, las medidas que sean necesarias para permitir el adecuado recurso a la entrega vigilada $\mathrm{y}$, cuando lo considere apropiado, la utilización de otras técnicas especiales de investigación, como la vigilancia electrónica o de otra índole y las operaciones encubiertas, por sus autoridades competentes en su territorio con objeto de combatir eficazmente la delincuencia organizada.

\section{b) Marco Nacional}

Código Nacional de Procedimientos Penales, establece las actuaciones en la investigación que no requieren autorización previa

\footnotetext{
${ }^{5}$ Manual de técnicas especiales de investigación agente encubierto y entrega vigilada, Oficina de las Naciones Unidas contra la Droga y el Delito, disponible: https://www.unodc.org/documents/ colombia/2013/diciembre/Manual_Tecnicas_Especiales_de_Investigacion_Bolivia.pdf, verificada el 09 de diciembre de 2015.
} 
del juez de control, en su artículo 251, estableciendo en su fracción IX, la entrega vigilada y las operaciones encubiertas, en el marco de una investigación y en los términos que establezcan los protocolos emitidos para tal efecto por el procurador; en los casos de esta fracción, dichas actuaciones deberán ser autorizadas por el procurador o por el servidor público en quien este delegue dicha facultad ${ }^{6}$.

En cuanto a su existencia formal de los agentes infiltrados en el ordenamiento nacional, ésta la ubicamos en los artículos 11 y 11 bis de la Ley Federal contra la Delincuencia Organizada.

Artículo 11.- En las averiguaciones previas relativas a los delitos a que se refiere esta Ley, la investigación también deberá abarcar el conocimiento de las estructuras de organización, formas de operación y ámbitos de actuación. Para tal efecto, el Procurador General de la República podrá autorizar la infiltración de agentes.

En estos casos se investigará no sólo a las personas físicas que pertenezcan a esta organización, sino las personas morales de las que se valgan para la realización de sus fines delictivos.

Artículo 11 Bis.- El Titular del órgano previsto en el artículo 8 podrá autorizar la reserva de la identidad de los agentes de la policía infiltrados, así como de los que participen en la ejecución de órdenes de aprehensión, detenciones en flagrancia y cateos relacionados con los delitos a que se refiere esta Ley, mediante resolución fundada y teniendo en cuenta el tipo de investigación, imposibilitando que conste en la averiguación previa respectiva su nombre, domicilio, así como cualquier otro dato o circunstancia que pudiera servir para la identificación de los mismos.

En tales casos, se asignará una clave numérica, que sólo será del conocimiento del Procurador General de la República, del Titular del órgano antes citado, del Secretario de Seguridad Pública y del servidor público a quien se asigne la clave.

En las actuaciones de averiguación previa, en el ejercicio de la acción penal y durante el proceso penal, el Ministerio Público y la autoridad judicial citarán la clave numérica en lugar de los datos de identidad del agente. En todo caso, el Ministerio Público acreditará ante la autoridad judicial el acuerdo por el que se haya autorizado el otorgamiento de la clave numérica y que ésta corresponde al servidor

6 Código Nacional de Procedimientos Penales, disponible: http://info4.juridicas.unam.mx/ijure/ fed/7/252.htm?s=, verificado el 29 de agosto de 2015 . 
público respectivo, preservando la confidencialidad de los datos de identidad del agente. En caso de que el agente de la policía cuya identidad se encuentre reservada tenga que intervenir personalmente en diligencias de desahogo de pruebas, se podrá emplear cualquier procedimiento que garantice la reserva de su identidad ${ }^{7}$.

\section{c) Ley de la Policía Federal}

Artículo 8. La Policía Federal tendrá las atribuciones y obligaciones siguientes:

VII. Llevar a cabo operaciones encubiertas y de usuarios simulados para la prevención de delitos. El Reglamento definirá con precisión los lineamientos mínimos para el ejercicio de esta atribución;

Artículo 10. Son atribuciones del Comisionado General de la Policía Federal:

XII. Autorizar, previo acuerdo con el Secretario, operaciones encubiertas y de usuarios simulados para desarrollar operaciones de inteligencia para la prevención. $^{8}$

\section{d) Reglamento de la Ley de la Policía Federal}

Artículo 22.- Corresponde a la Coordinación de Operaciones Encubiertas:

I. Dirigir la realización de operaciones encubiertas y de usuarios simulados con el objeto de asegurar la obtención, análisis y explotación de información con el propósito de prevenir y, bajo la conducción y mando del Ministerio Público, combatir la comisión de delitos;

II. Diseñar y operar métodos para llevar a cabo operaciones encubiertas y de usuarios simulados, que tengan por objeto asegurar la obtención, análisis y explotación de información con la finalidad de prevenir y, bajo la conducción y mando del Ministerio Público, combatir la comisión de delitos;

III. Establecer estrategias de prevención, acción y de movilización de recursos, a través de operaciones encubiertas y de usuarios simulados, con el propósito de evitar la comisión de probables hechos delictivos;

IV. Estudiar, planificar y ejecutar métodos y técnicas de operaciones encubiertas y de usuarios simulados previo acuerdo del Comisionado General y del Secretario para la prevención del delito;

\footnotetext{
${ }^{7}$ Ley Federal contra la Delincuencia Organizada, disponible http://www.diputados.gob.mx/LeyesBiblio/ ref/Ifcdo.htm, verificada el 16 de octubre de 2015.

8 Ley de la policía Federal, disponible: http://www.diputados.gob.mx/LeyesBiblio/doc/LPF.doc, verificado el 30 de agosto de 2015.
} 
V. Establecer esquemas de investigación preventiva a través de la infiltración de agentes para la obtención de información de estructuras criminales, formas de operar y ámbitos de actuación en términos de las normas aplicables;

VI. Fortalecer la prevención primaria de la criminalidad, a través de acciones encubiertas y de usuarios simulados, con el fin de obtener información;

XIII. Orientar la investigación de las operaciones encubiertas y de usuarios simulados que implemente la Institución para el cumplimiento de sus fines;

XV. Dirigir y sistematizar, operaciones encubiertas o de usuarios simulados que implemente la Institución para el cumplimiento de sus fines;

XIX. Las demás que le confieran este Reglamento, otras disposiciones legales aplicables o aquéllas que le encomiende el inmediato superior de quien dependa ${ }^{9}$.

\section{e) La postura de la Suprema Corte de Justicia de la Nación}

El Pleno de la Suprema Corte de Justicia de la Nación (SCJN) validó, por mayoría de votos, el que la Policía Federal lleve a cabo operaciones encubiertas y de usuarios simulados para la prevención de delitos, conforme a los lineamientos que establezca el reglamento, no vulnera garantías constitucionales.

De igual manera, los ministros declararon como constitucional la facultad que le confiere la Ley de la Policía Federal al Comisionado General de autorizar operaciones encubiertas y de usuarios simulados para desarrollar operaciones de inteligencia para la prevención del delito, lo que no resulta contrario al principio de certeza consagrado en el artículo 14 constitucional.

Así, el Alto Tribunal resolvió la acción de inconstitucionalidad 48/2009 promovida por la Comisión Nacional de los Derechos Humanos en contra de diversos artículos de la Ley de la Policía Federal y la Ley Orgánica de la Procuraduría General de la República, al argumentar que resultan contrarios a la Carta Magna.

Los ministros indicaron que se debe considerar que las garantías de certeza y de seguridad jurídica, reconocidas en el artículo 14 constitucional, consisten en el derecho del gobernado -al que, en un momento dado, se le pretenda privar de una prerrogativa establecida en la ley- de ser sujeto a un juicio en el cual pueda dilucidar sus

\footnotetext{
${ }^{9}$ Reglamento de la Ley de la Policía Federal, disponible: http://www.dof.gob.mx/nota_detalle.php?co digo $=5143004 \&$ fecha=17/05/2010, verificado el 30 de agosto de 2015 .
} 
derechos, ante tribunales previamente establecidos, en el que se observen las formalidades esenciales del procedimiento, y que el fallo correspondiente, se dicte de conformidad con leyes expedidas con anterioridad al hecho o circunstancia que motivó el juicio

Además, precisó el Pleno de la SCJN que en aras de asegurar al gobernado la salvaguarda de tales derechos y con la finalidad última de proteger su persona, familia, posesiones o derechos, frente a cualquier acto de autoridad, que pretenda limitarlos, el artículo 14 constitucional establece un conjunto de condiciones y requisitos a los que previamente debe sujetarse la autoridad para que su actuación genere una afectación válida en la esfera jurídica del individuo, condiciones y requisitos a los cuales deben sumarse los que se establezcan en las leyes ordinarias aplicables.

En ese sentido, precisaron los ministros, la norma impugnada, por sí sola, en cuanto remite al reglamento, no vulnera las garantías de certeza y de seguridad jurídica, pues dicha prerrogativa tiene por objeto limitar la actuación de las autoridades, frente a la inminente privación o afectación de un bien jurídico tutelado, situación que, en el caso, se satisface, al no contraponerse la tutela de dicha garantía con la facultad reglamentaria del titular del Poder Ejecutivo.

En todo caso, señalaron, sería el reglamento el que en caso de ser deficiente, podría vulnerar dicha garantía y, en su caso, se tienen las vías legales para combatirlo, o bien, para impugnar la actuación que fuera del marco legal llegase a efectuar algún miembro de la policía federal al llevar a cabo las citadas actividades. ${ }^{10}$

\section{f) La iniciativa de Ley de la Fiscalía General de la República}

La Comisión de Justicia de la Cámara de Diputados autorizó la infiltración de agentes y las operaciones encubiertas para realizar investigaciones de tipo penal, esta Comisión avaló por unanimidad la iniciativa de ley de la Fiscalía General de la República, que sustituirá a la actual Procuraduría General de la República (PGR), esta fue enviada el 23 de septiembre por el Presidente de la República, Enrique Peña Nieto.

\footnotetext{
${ }^{10}$ REGULACIÓN DE OPERACIONES ENCUBIERTAS Y DE USUARIOS SIMULADOS POR PARTE DE POLICÍA FEDERAL EN UN REGLAMENTO, NO VULNERA GARANTÍAS CONSTITUCIONALES, Comisionado General de la Policía puede autorizar operaciones encubiertas y de usuarios simulados para desarrollar operaciones de inteligencia para la prevención del delito, resolvieron los ministros, Acción de inconstitucionalidad 48/2009 promovida por la Comisión Nacional de los Derechos Humanos, disponible: https://www.scjn.gob.mx/saladeprensa/noticias/Paginas/14-Abril-2011.aspx, verificado el 09 de diciembre de 2015.
} 
En su artículo 13, que habla de las facultades del nuevo fiscal federal, se establece en su fracción sexta: "autorizar la infiltración de agentes para investigaciones así como los actos de entrega vigilada y las operaciones encubiertas previstas en la ley y en los tratados internacionales ratificados por el Estado Mexicano".

El mismo artículo, pero en su fracción 2, establece que el mismo fiscal podrá solicitar a los concesionarios de telecomunicaciones la localización geográfica "en tiempo real" de los equipos de comunicación civil.

La nueva ley otorga autonomía a la nueva Fiscalía General de la República, lo cual significa que ya no dependerá del Poder Ejecutivo y el cargo será transexenal.

El tiempo en que dure como titular el nuevo fiscal será de nueve años y según los argumentos del Ejecutivo federal ello asegurará la independencia del fiscal y la continuidad de las políticas públicas que establezca.

El dictamen no tuvo reclamos de ningún partido por lo que se refiere a la autorización de infiltrar agentes y emprender operaciones encubiertas ${ }^{11}$.

\section{Operaciones encubiertas en el periodo del 2006-2012}

El gobierno de Felipe Calderón destino 12 mil millones de pesos a operaciones encubiertas, como infiltrar al narcotráfico, tener una nómina de informantes o mantener en el exilio a testigos protegidos.

Ciudad de México. ¿Cuánto cuestan las operaciones más peligrosas del gobierno mexicano? ¿Qué tan caro sale infiltrar al narcotráfico? ¿O crear una nómina de informantes? ¿O tender trampas a narcos y mantener en el exilio a testigos protegidos? La respuesta: casi mil millones de dólares.

Tras el escudo del secreto de Estado, el gobierno de Felipe Calderón destino a lo largo del sexenio hasta 12 mil millones de pesos para financiar "gastos confidenciales" en el combate al crimen

\footnotetext{
${ }^{11}$ Avalan infiltración de agentes y operaciones encubiertas en indagatorias penaleshttp://www. proceso. com.mx/?p=390299, disponible: http://gaceta.diputados.gob.mx/PDF/62/2014/sep/20140923-IX. pdf, verificado el 10 de diciembre de 2015.
} 
organizado, dinero que habría sido empleado en distintos rubros clasificados, desde pagar operaciones encubiertas y rentar casas de seguridad, hasta preparar operativos sorpresa para capturar a capos del narcotráfico.

La partida que se utiliza para "gastos de seguridad pública y nacional" es la conocida como la partida 33701 y opera bajo la más estricta reserva del Estado Mexicano. Su uso es tan confidencial que, por ley, sólo algunos secretarios, el procurador General de la República y el titular del CISEN tienen autorización para activarla. Y sólo ellos saben a qué exactamente ha sido destinada.

Pero si bien es secreta, su uso ha sido extenso y millonario: 9 dependencias del gobierno federal, incluidas las Fuerzas Armadas y los servicios de inteligencia, se han visto beneficiadas con acceso a cientos de millones de pesos provenientes de la partida, que pueden ser empleados para financiar una amplia gama de acciones, según se desprende de informes de la Auditoría Superior de la Federación, el Diario Oficial de laFederación y reglamentos internos gubernamentales. En realidad, es un gasto que queda a la libre interpretación de cada dependencia.

Según distintos registros, para la Policía Federal y la Secretaría de Seguridad Pública la partida 33701 cubre los gastos en operaciones encubiertas y con usuarios simulados, además de financiar el costo de infiltrar agentes en redes criminales.

La cifra del gasto ejercido dentro de esta partida es mayúscula. Tanto como difícil es definir en qué se invierten sus recursos por obvias razones: un cálculo realizado por este diario detalla que el monto asignado a erogaciones confidenciales desde 2006 es casi once veces el presupuesto de la Presidencia de la República (mil 700 millones) o dos veces más que el programa Oportunidades (5 mil millones de pesos).

La Policía Federal dio algunos detalles adicionales de lo que se hace con gasto a la partida más secreta del gobierno: "El presupuesto ejercido en Gastos de Seguridad Pública y Nacional es utilizado para atender los requerimientos de los diversos operativos confidenciales. A través de operaciones encubiertas, trabajo de inteligencia, intercambio de información con otras instituciones de Seguridad Nacional y corporaciones policiales del ámbito estatal y municipal".

Conocidas comúnmente como "operaciones negras", en la Policía 
Federal este tipo de actividades están a cargo de la Coordinación de Operaciones Encubiertas, un área que de acuerdo a su reglamento interno puede trabajar con "usuarios simulados" y obtener información por vías diversas, como la infiltración de agentes encubiertos en estructuras criminales. Es decir, de la partida se pagan los salarios de un número altamente secreto de hombres y mujeres que han logrado infiltrar a las redes criminales del país.

La Policía Federal reveló que desde el 2006 se han transferido a sus operaciones confidenciales más de 5 mil 300 millones pesos, equivalente a casi 400 millones de dólares al tipo de cambio actual.

De manera pública, la Policía Federal sólo ha informado de dos operaciones encubiertas que han sido sufragadas con cargo a la partida confidencial. Una de ellas, con nombre clave "Colmena", permitió en marzo pasado la captura de Víctor Manuel Félix, compadre de Joaquín el Chapo Guzmán y cabeza de una célula dedicada al tráfico de drogas entre Sudamérica y México.

En 2010, otra operación encubierta -mediante la cual se crearon cuentas bancarias ficticias, llevó a la caída de Javier López Medina, lugarteniente de la Familia Michoacana. ${ }^{12}$

\section{a) Resultados de operaciones encubiertas en el año 2014}

El área de Operaciones e Infiltración de la Policía Federal (PF) logró detener en 2014 a un total de 84 presuntos integrantes de grupos criminales que operaban en entidades como Guerrero, Michoacán, Jalisco y el Distrito Federal.

Funcionarios que participan en el gabinete de seguridad nacional revelaron que este grupo de la Policía Federal es uno de los más activos en cuanto a infiltración de grupos criminales dedicados al narcotráfico y secuestro.

Mediante solicitudes de información pública, la Comisión Nacional de Seguridad y la Policía Federal revelaron que dentro de la estructura de la Dirección General de Operaciones existe el área de infiltración, que depende de la Coordinación de Operaciones Encubiertas.

12 Mil millones de dólares: la partida secreta del gobierno mexicano, México, 7 Noviembre de 2011, Periódico Vanguardia, disponible: http://www.vanguardia.com.mx/ milmillonesdedolareslapartidasecretadelgobiernomexicano-1141936.html, verificado el 08 de septiembre de 2015. 
Las tareas que realiza esta área -de la cual no se ha revelado el número de sus elementos- son obtener datos que aporten información sustantiva sensible de aquellos casos determinantes en la prevención y, en el ámbito de su competencia, combate al delito.

Para ello, deben realizar trabajo de campo con personal y equipo técnico que permita la obtención de información sustantiva para la prevención, y la ley les permite llevar a cabo operaciones encubiertas y de usuarios simulados para la prevención de los delitos.

En cuanto al tipo de armamento, equipo táctico y vehículos con que cuentan estas células operativas, la Comisión Nacional de Seguridad reservó la información por 12 años, pues señaló que darlo a conocer pondría en peligro la integridad y derechos de las personas que laboran en esas áreas.

Proporcionar información sobre la cantidad exacta de policías federales, así como cuántos vehículos y de qué tipo se tienen, es suficiente para facilitar un plan de atentado en el que se deje en desventaja el actuar policial y por consecuencia, imposibilite el debido cumplimiento de sus funciones, señaló la Policía Federal.

Sin embargo, las operaciones de estas células permitieron que en 2014 se lograra la aprehensión de 84 presuntos responsables de la comisión de diversos delitos, también en entidades como Tlaxcala, Morelos y Querétaro ${ }^{13}$.

\section{A manera de conclusión}

Sin protocolos ni transparencia que garanticen su legalidad y eficacia, las operaciones de infiltración, enfocadas en la seguridad pública, han ido convirtiéndose en actividades primordiales para los servicios secretos civiles y militares mexicanos, como parte de sus atribuciones de inteligencia.

Debido a la falta de información con el argumento de que de proporcionar datos sobre las operaciones encubiertas, vulnera la

${ }^{13}$ Castillo García, Gustavo, Área de infiltración de la PF detuvo a 84 en 2014, disponible: http://www. jornada.unam. $\mathrm{mx} / 2015 / 04 / 18 /$ index.php?section=politica\&article=014n 2 pol, verificado el 11 de diciembre de 2015. 
seguridad nacional y la seguridad pública, no es posible medir su eficacia ni garantizar que no saldrán de control.

La Ley Federal contra la Delincuencia Organizada faculta a la Procuraduría General de la República para realizar operaciones de infiltración, pero no al Centro Nacional de Información y Seguridad Nacional (Cisen), ni a las Secretarías de Defensa y Marina. El Gobierno Federal mantiene una agenda secreta que ha implicado este tipo de operaciones como parte de la estrategia para debilitar a las organizaciones de narcotraficantes.

Algunos de los objetivos del "Programa para la Seguridad Nacional"; implican que los organismos de inteligencia podrán hacer monitoreos para "detectar y acotar intentos de la delincuencia organizada", y coadyuvar a "elevar el nivel de eficacia en la integración de averiguaciones previas" en el Ministerio Público, con "productos de inteligencia".

Con la publicación del Reglamento de la Policía Federal se dio la entrada a los agentes encubiertos a cargo de la Secretaría de Seguridad Pública federal (SSP) y se acabó con la existencia de la Policía Federal Preventiva. Los policías encubiertos, tendrán un nombre clave que sólo será conocido por tres funcionarios. Se "permitirá" a los encubiertos realizar actividades ilícitas durante las operaciones, siempre que sean necesarias, y no podrán ser acusados penalmente. Deberán someterse a un control de confianza.

La Dirección General de Operaciones Encubiertas e Infiltraciones, de la División de Inteligencia, a cargo de Maribel Cervantes, encabeza los operativos para recabar datos que permitan identificar y atrapar bandas criminales y combatir la comisión de delitos. Los funcionarios que autorizarán las operaciones serán el Comisionado General de la Policía Federal y el titular de la Secretaría de Seguridad Pública, quienes revisarán todos los ángulos del caso a tratar antes de permitir la labor de sus agentes.

El Comisionado General de la Policía Federal, el jefe de Inteligencia y el coordinador de Operaciones Encubiertas serán los únicos que podrán conocer la identidad de los agentes.

Cuando las investigaciones terminen en aprehensiones, cateos o detenciones en el momento, el Ministerio Público suprimirá de los documentos cualquier referencia que permita saber la identidad. Sólo se podrán manejar claves numéricas. 
Este tipo de actividades obscuramente reguladas en la ley, permiten a la autoridad realizar actos desconocidos por la sociedad, que en muchos de los casos vulnerara los derechos fundamentales de las personas involucradas en las operaciones encubiertas, el principal argumento de la autoridad para llevar a cabo este tipo de acciones es que se utiliza como una técnica de investigación penal.

Tendríamos también que analizar el hecho de que las pruebas obtenidas en las operaciones encubiertas podrían considerarse ilícitas ya que en muchos de los casos son obtenidas sin cumplir con los requisitos de ley para su obtención.

Ya lo refería el ministro de la SCNJ, Juan N. Silva Meza, que la posibilidad de avalar el reglamento de operaciones encubiertas, elaborado por el Ejecutivo Federal es inconstitucional, porque sus técnicas presentan un alto riesgo de afectar la seguridad e integridad de las personas involucradas y de restringir o afectar sus derechos fundamentales. Las operaciones encubiertas no pueden ser reguladas con el control absoluto y discrecional del presidente de la república y su gabinete, se requiere una legislación formal y material aprobada por el Congreso que contemple un control judicial de los operativos.

Las operaciones encubiertas, como en el caso de delitos graves y los relacionados con la delincuencia organizada, deben tener un control judicial previo; es decir, que el Procurador de la República o el Comisionado General de la Policía Federal tengan la autorización de un juez competente, quien debe analizar si el objetivo del operativo que se pretende hacer está apegado a las leyes, a la Constitución y los tratados Internacionales de la materia.

Otra situación que se debe considerarse es si el agente encubierto que realice la acción aun cuando sea comisivo de un delito ¿no se procederá penalmente en su contra? Es decir ¿su actuar dentro de una operación encubierta surtirá los efectos de una excusa absolutoria por la comisión de delitos?

Los derechos fundamentales tienen protección constitucional y ni la ley ni un reglamento pueden autorizar investigaciones que sean contrarias a los derechos humanos fundamentales, en todo caso si en la implementación de las operaciones encubiertas son violadas garantías consagradas en la constitución o en instrumentos internacionales, deberán existir mecanismos legales que cuestionen la legalidad de dichas acciones. 
Las operaciones encubiertas implican la realización de una multiplicidad de actos de autoridad, que pueden llegar a tener una injerencia grave en los derechos fundamentales de los particulares objeto de las mismas, como puede ser el derecho a la intimidad, la inviolabilidad del domicilio y de las comunicaciones privadas o el derecho del procesado a conocer el nombre de quien lo acusa, por mencionar algunas.

Es clara y evidente la posibilidad de que en la realización de las correspondientes operaciones se cometan violaciones a los derechos humanos, en contra de los principios de certeza y legalidad, debido a que la ley que crea y autoriza la realización de estas actividades no contemplan lineamientos mínimos bajo los cuales se deben regir las operaciones encubiertas, constituyendo en realidad como una ley en blanco, que amplía el margen de la actuación de la norma reglamentaria que, por virtud de esta atribución, podrá reglar aspectos sustantivos que sólo corresponden a la ley por disposición constitucional.

La ley es omisa en cuanto a los lineamientos que deben regir la figura del policía encubierto, pues de forma alguna especifica cuál será su proceder durante la realización de estas operaciones, por lo que no se sabe si la labor del agente encubierto sólo podrá realizarse con la anuencia del mismo, o bien, eventualmente podría obligársele a realizarlo y, por lo tanto, a cometer conductas delictuosas en perjuicio de su libertad de conciencia, además tampoco especifica si dichos agentes estarán legitimados para la comisión de delitos durante la realización de las operaciones, y tampoco se establecen normas para la protección de la identidad e integridad de la persona ni se prohíbe que en el desempeño de su misión inciten o provoquen un delito que en condiciones normales no se habría cometido.

Es de suma importancia que la ley contemple una regulación detallada entorno a esta problemática pues, desde la perspectiva de los derechos fundamentales, resulta relevante contar con un régimen legal claro y detallado, no sólo en cuanto a los derechos y la protección con que deben contar estos policías, sino también en torno a las obligaciones, límites y responsabilidades a los que están sujetos.

Así pues resulta evidente la manera en que dichas omisiones en la ley transgreden de manera grave, no sólo los derechos de las personas que en determinado momento puedan ser sujetas de una investigación por parte de un agente encubierto, sino también los derechos de los mismos agentes. 
Las operaciones encubiertas transgreden los derechos fundamentales, por lo que es preciso que se consideren actividades de tipo extraordinario, que deben regirse por los principios de legalidad, proporcionalidad y subsidiariedad ${ }^{14}$.

Bibliografía
Guillen López, Germán, La investigación criminal en el sistema penal acusatorio, disponible: http:// biblio.juridicas.unam.mx/libros/libro.htm?l=3454, verificada el 03 de diciembre de 2015

Rivero Evia, Jorge, Los agentes clandestinos y el debido proceso, Revista del Instituto de la Judicatura Federal No. 28, disponible: http:// www.ijf.cjf.gob.mx/publicaciones/revista/28/Los agentes_clandestinos.pdf, verificada el 06 de diciembre de 2015.

Lamarre,Flavia,Agentesencubiertosycriminalidad organizada: Derecho y Demagogia, Lecciones y Ensayos, nro. 88, 2010, disponible: http://www. derecho.uba.ar/publicaciones/lye/revistas/88/ lecciones-y-ensayos-88-paginas-175-195.pdf, verificada el 26 de noviembre de 2015 .

Del Pozo Pérez, Marta, El agente encubierto como medio de investigación de la delincuencia organizada en la ley de enjuiciamiento criminal española, disponible: http://revistas.javerianacali. edu.co/index.php/criteriojuridico/article/ viewFile/260/1023, verificada el 03 de octubre de 2015.

Manual de técnicas especiales de investigación agente encubierto y entrega vigilada, Oficina de las Naciones Unidas contra la Droga y el Delito, disponible: https://www.unodc.org/documents/ colombia/2013/diciembre/Manual Tecnicas

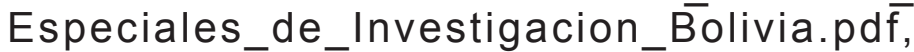
verificada el $\overline{0} 9$ de diciembre de $20 \overline{15}$.

\footnotetext{
${ }^{14}$ Seminario Judicial de la Federación y su Gaceta, Novena época, pleno, tomo XXXIV, julio de 2011, pagina 1207, disponible: http://sjf.scjn.gob.mx/sjfsist/Paginas/DetalleGeneralScroll.aspx?id=22998\&C lase=DetalleTesisEjecutorias
} 
Ley Federal contra la Delincuencia Organizada, disponible http://www.diputados.gob.mx/ LeyesBiblio/ref/ffcdo.htm, verificada el 16 de octubre de 2015.

Ley de la policía Federal, disponible: http://www. diputados.gob.mx/LeyesBiblio/doc/LPF.doc, verificado el 30 de agosto de 2015.

Reglamento de la Ley de la Policía Federal, disponible: http://www.dof.gob.mx/nota_detalle. php? codigo $=5143004 \&$ fecha $=17 / 0 \overline{5} / 2010$, verificado el 30 de agosto de 2015.

REGULACIÓN DE OPERACIONES ENCUBIERTAS Y DE USUARIOS SIMULADOS POR PARTE DE POLICÍA FEDERAL EN UN REGLAMENTO, NO VULNERA GARANTÍAS CONSTITUCIONALES, Comisionado General de la Policía puede autorizar operaciones encubiertas y de usuarios simulados para desarrollar operaciones de inteligencia para la prevención del delito, resolvieron los ministros, Acción de inconstitucionalidad 48/2009 promovida por la Comisión Nacional de los Derechos Humanos, disponible: https://www.scjn.gob.mx/ saladeprensa/noticias/Paginas/14-Abril-2011. aspx, verificado el 09 de diciembre de 2015.

Avalan infiltración de agentes y operaciones encubiertas en indagatorias penaleshttp:// www. proceso.com. $m x / ? p=390299$, disponible: http://gaceta.diputados.gob.mx/PDF/62/2014/ sep/20140923-IX.pdf, verificado el 10 de diciembre de 2015.

Mil millones de dólares: la partida secreta del gobierno mexicano, México, 7 Noviembre de 2011, Periódico Vanguardia, disponible: http://www.vanguardia.com.mx/ milmillonesdedolareslapartidasecretadelgobierno mexicano-1141936.html, verificado el 08 de septiembre de 2015. 
Castillo García, Gustavo, Área de infiltración de la PF detuvo a 84 en 2014, disponible: http://www. jornada.unam.mx/2015/04/18/index.php?sectio $\mathrm{n}=$ politica\&article $=014 \mathrm{n} 2 \mathrm{pol}$, verificado el 11 de diciembre de 2015.

Seminario Judicial de la Federación y su Gaceta, Novena época, pleno, tomo XXXIV, julio de 2011, pagina 1207, disponible: http://sjf.scjn.gob.mx/ sjfsist/Paginas/DetalleGeneralScroll.aspx?id=22 998\&Clase=DetalleTesisEjecutorias 